\title{
CHANGE OF GEOMETRY OF ECAP CHANNEL TO INCREASE DEFORMATION INTENSITY BY SPD PROCESS OF AIMn1CU AND AZ 31 ALLOYS
}

\author{
${ }^{1}$ Jakub TILL, ${ }^{1}$ Stanislav RUSZ, 'Lubomir ČíŽEK, ${ }^{1}$ Michal SALAJKA, ${ }^{2}$ Karel MALANÍK, \\ ${ }^{3}$ Eugeniusz HADASIK, ${ }^{4}$ Marcel KLOS
}

${ }^{1}$ VSB - Technical University of Ostrava, Faculty of Mechanical Engineering, Ostrava, Czech Republic, EU, jakub.till.st@vsb.cz

${ }^{2}$ Research Institute of Iron and Metallurgy Dobra, Dobra, Czech Republic, EU

${ }^{3}$ Silesian University of Technology Katowice, Faculty of Materials Engineering and Metallurgy, Katowice, Poland, EU

${ }^{3}$ Tatra Trucks, a.s., Koprivinice, Czech Republic, EU

https://doi.org/10.37904/metal.2019.823

\begin{abstract}
Currently, technological progress in many modern industries requires in implementation of new types of technical materials and related development of new manufacturing technologies that bring both enhancement of service properties of final products, as well as their wider implementation into engineering practice, including the associated energy savings. One possibility is also a constant increasing of consumption of non-ferrous metals. Sustainable development of human society is subject to a maximum economy of non-renewable sources of energy and raw materials, especially metallic ones. One of the ways for achieving this goal, in addition to recycling waste alloys based on aluminium, copper and magnesium, is systematic reduction of their consumption by increasing their quality and service life of utility objects and structures made from them. Already for many years, this happens in metallurgical production for example by alloying or by heat treatment. Production of reinforcing steel by cold deformation by twisting or by tension has brought Significant savings in civil engineering. In this way a significant increase of the yield point and its shifting to the ultimate strength was thus achieved at small decrease in ductility. Technical and economic benefits are obvious: metallurgical irreversible consumption of metals and of financial costs related to it were reduced at producers.

One of the ways to the more effective use of metallic materials is their processing by forming. At present in this the area the use of the process of multiple severe plastic deformation (SPD process), leading to a refinement of the structure (materials with UFG structure) and thus to achievement of higher level of their utility value, is expanding.
\end{abstract}

Keywords: Metallurgy, steel, properties, applications, testing methods, SPD process

\section{INTRODUCTION}

The most important mechanism of cold and hot plastic deformation is dislocation slip, which is the most evident under the shear stress load. It is one of the main pre-requisites at designing the methods based on the use of the SPD process. The effect was observed mainly in metals and alloys with cubic face-centred lattice, characterized by a high number of slip systems (Al, $\mathrm{Cu}, \mathrm{Ni})$ [1-10].

The process of plastic deformation, which leads to a refinement of the structure, depends on several factors. In addition to the mentioned lattice structure the following factors are involved: the structure before deformation (grain size, microstructure), the second phase particles, strain rate and temperature of deformation, magnitude of deformation, the route of deformation. Mechanisms of grain refinement vary depending on the magnitude of deformation divided the influence of the magnitude of an increase of deformation into four areas [3]. This concerns evaluation of results achieved during deformation of metals with cubic face-centred lattice ECAP (ECAP-principle - see below at description of the proposed project), using the deformation route BC: small 
strain intensity $(\varepsilon \vee M<2)$, small to moderate strain intensity $(\varepsilon \vee M=2-4)$, moderate to high strain intensity $(\varepsilon \vee M$ $=4-6)$, extreme strain intensity - SPD $(\varepsilon \bigvee M>6)$

Ultra fine-grained materials (UFG) are defined as poly-crystals with average grain size in the range from 100 $\mathrm{nm}-1000 \mathrm{~nm}$, i.e. less than $1 \mu \mathrm{m}$. UFG materials include also nano-materials with grain sizes ranging from 10 $\mathrm{nm}-100 \mathrm{~nm}$. Growing interest in UFG materials arises mainly for two reasons. Firstly, it is known that in all the alloys the Hall-Petch mechanism [4] contributes to strengthening of the material at room temperature according.

\subsection{The basic methods of production of UFG materials are the following}

ECAP - Equal Channel Angular Pressing, DCAP - Dissimilar Channel Angular Pressing, HPT - High Pressure Torsion, CCDC - Cyclic Channel Die Compression, CEC - Cyclic Extrusion Compression, CONFORM Continuous Extrusion Forming, ARB - Accumulative Roll Bonding, CGP - Constrained Groove Pressing, TE Twist Extrusion

Designing a new concept of development of the process of severe plastic deformation in terms of achieving greater efficiency. The essence of the SPD process (severe plastic deformation) - ECAP method.

ECAP is one of the most intensively developed methods of grain refinement in the material. High degree of deformation is achieved in the whole volume of the formed sample, which gives very good pre-requisites for industrial applications. The ECAP method is based on extrusion of the sample through the tool with an internal $L$ shaped channel, without any change of cross-section of the sample, as it is evident from Figure 1. The sample is inserted from above into the vertical channel and then extruded through the tool [7]. This operation is then repeated in order to achieve the required degree of deformation of the material leading to a refinement of the structure. It is possible to use in the process various types of changes of the route of deformation.

The route A is used for processing of materials with longitudinal precipitates, where the sample is repeatedly extruded without any rotation. The route $\mathrm{BC}$ is suitable for obtaining homogeneous micro-structures with high angle of grain boundaries, where the sample is rotated between each pass by $90^{\circ}$. The routes $\mathrm{BA}$ and $\mathrm{BC}$ rotate by $90^{\circ}$, the difference is in the sense of rotation between individual extrusions.

The route $\mathrm{C}$ shows rotation of the sample by $180^{\circ}$ at each passes (Figure 1). Some researches indicate that the route $B C$ is by $40 \%$ more efficient than the route $C$ and almost by $50 \%$ more efficient than the route $A$ [4]. It has also been proven that for production of homogenous structure of the material the quadruple extrusion using the route $\mathrm{BC}$ is the most advantageous. Elimination of low angles of grain boundaries and obtaining of higher angles, depending on the material, requires six and more extrusions [8]. Figure 3 shows the shear planes at individual routes depending on the number of extrusions.
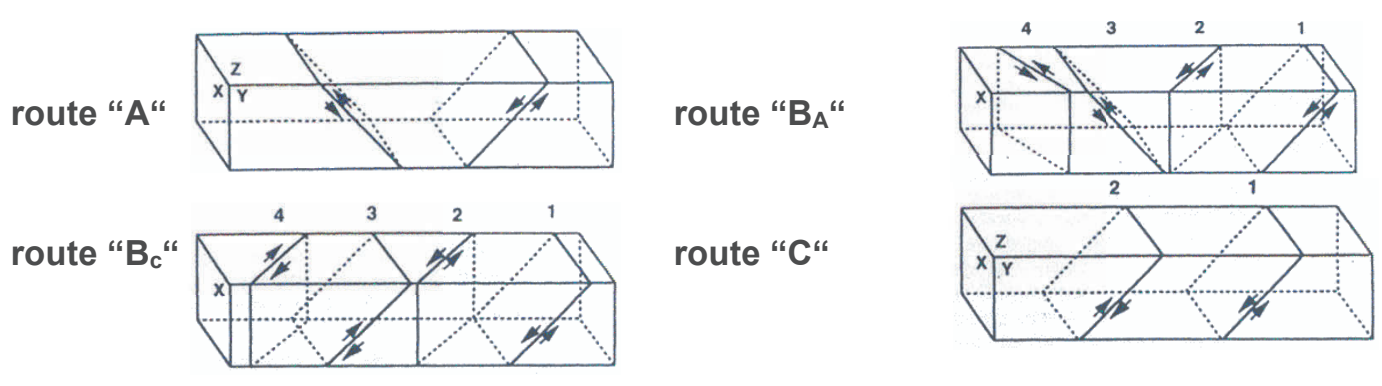

Figure 1 Formation of shear planes at independent routes of deformation by extrusion

\section{NEW CONCEPT - METHOD TWIST EXTRUSION (TE - EXTRUSION WITH BUILT-IN HELIX)}

TE is based on extrusion of the sample of prismatic cross-section through the tool with the profile consisting of two prismatic parts separated by a helical part (see Figure 2). Cross-section at TE remains unchanged. 
This feature makes it possible to extrude the sample repeatedly in order to accumulate the strain needed to change the micro-structure and mechanical properties of the sample material [10].

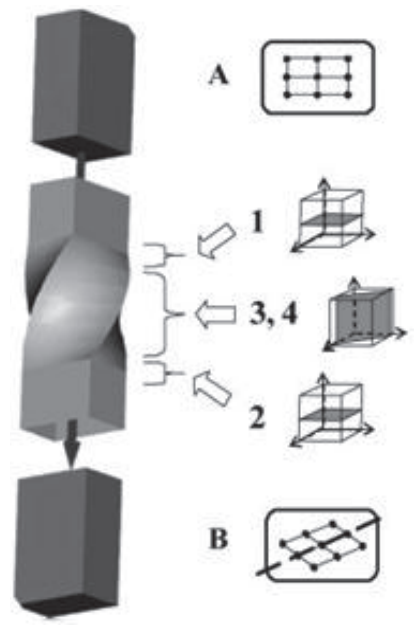

Figure 2 Principle of the Twist Extrusion Process

Technological possibilities of the TE method compared with the ECAP method:

- Magnitude of termination of the deformed area of the sample at the input and output part of the sample is much lower in TE than in ECAP. This is a feature, which is very important for repeating of passes.

- Change of the sample profile occurs at the central part of the axial channel [9].

- $\quad T E$ can be easily installed on the standard equipment of the press by replacement of traditional tools by the tool with rotary channel (helix).

- Tool (TE) does not change the direction of movement of the sample, which enables its simple inclusion into the existing tools on the presses and thus integration of this equipment into a production line [6].

The proposed project will verify the totally new concept of the forming tool - called ECAP + TE (ECAP tool with built-helix in the horizontal channel - see Figure 3).

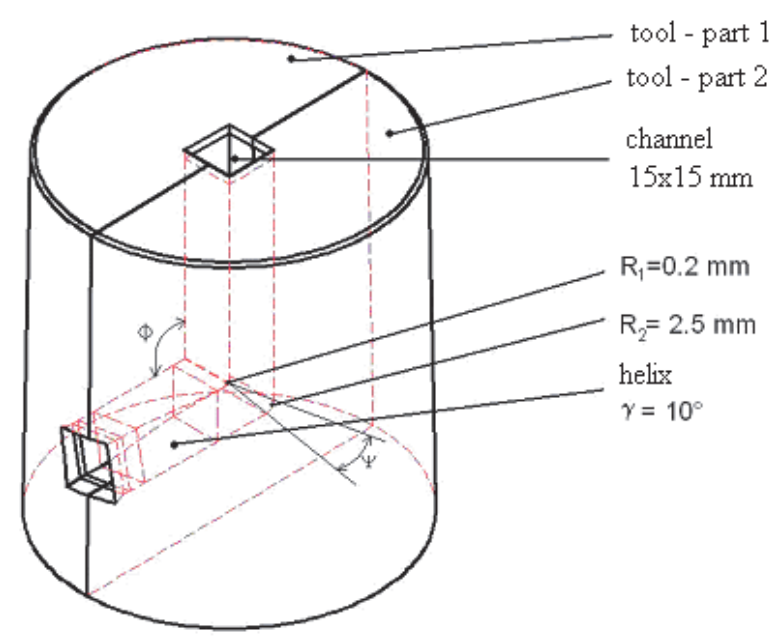

Figure 3 Insert of the ECAP tool with built-in helix

This new approach will make it possible to significantly increase the efficiency of the process of severe plastic deformation (SPD). The material will be strengthened very intensely, allowing us to achieve a high degree of deformation of material at a lower number of passes through the forming tool. At the same time high 
homogeneity of the structure will be achieved. We want to realize the verification of the results in collaboration with the Žilina University, Faculty of Mechanical Engineering. The selected type of material will be pressed through the ECAP tool with back counter-pressure. The principle of the method is shown in Figure 4. The results achieved by both methods will be mutually compared.

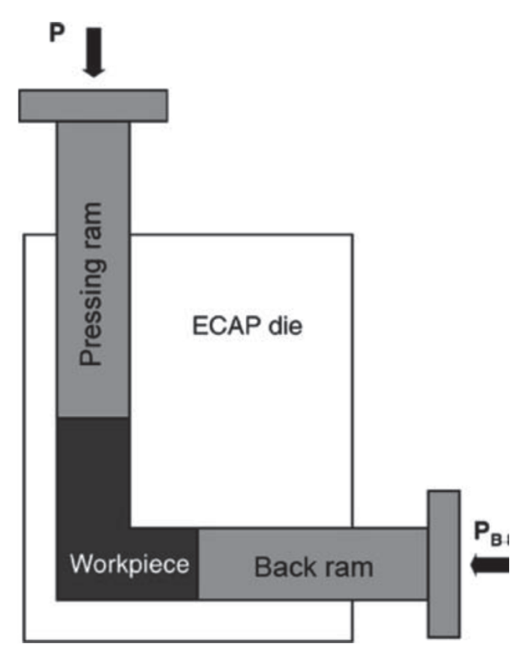

Figure 4 The principle of the ECAP method with back pressure

\section{EXPERIMENTAL MATERIALS AND PROCEDURES}

AIMn1Cu alloy is commercially produced aluminum alloy by the company AL INVEST (the cast strip with a mild reduction by rolling up to $10 \%$ to the thickness of 10 and $15 \mathrm{~mm}$, which has its uses especially in engineering. Chemical composition of the AIMn1Cu alloy is given in Table 1. AZ31 alloy is commercially produced aluminum alloy after casting and extrusion at $400{ }^{\circ} \mathrm{C}$ on final rod with $20 \mathrm{~mm}$ diameter [11]. Chemical composition of the AZ31 alloy is given in Table 2. For experimental purposes from the belts of alloys the test samples of the underlying dimensions of $10 \times 10 \mathrm{~mm}$ length $40 \mathrm{~mm}$ (geometry with channel deflection $20^{\circ}$ ) and $15 \times 15 \mathrm{~mm}$ length $60 \mathrm{~mm}$ (geometry with helix matrix) in the direction of rolling were made [12].

Table 1 Chemical composition of AIMn1Cu alloy

\begin{tabular}{|l|l|l|l|l|l|l|}
\hline Element & $\mathrm{Si}$ & $\mathrm{Fe}$ & $\mathrm{Cu}$ & $\mathrm{Mn}$ & Other & $\mathrm{Al}$ \\
\hline [wt\%] & 0.55 & 0.45 & 0.15 & 1.1 & 0.15 & Rest \\
\hline
\end{tabular}

Table 2 Chemical composition of AZ31 alloy

\begin{tabular}{|l|l|l|l|l|l|l|}
\hline Element & Al & Zn & $\mathrm{Cu}$ & Mn & Other & Mg \\
\hline$[w t \%]$ & 3.07 & 0.765 & 0.0016 & 0.246 & 0.15 & Rest \\
\hline
\end{tabular}

\section{INFLUENCE OF THE NUMBER OF PASSES ON THE STRESS -STRAIN CURVES}

The results of experiments conducted on hydraulic press DP $1600 \mathrm{kN}$, was shown a significant effect modification of the geometry tools ECAE curves deformable resistance and thus hardening the AIMn1Cu and magnesium AZ91 alloys each channel passes [13]. According to the assumptions underlying the increase deformable resistance occurs in all the instruments of ECAP with increasing number of passes. Figure $\mathbf{5}$ 
shows selected readings stress-strain curves after selected passes through the channel for AIMn1Cu alloy. Very good results were achieved in both alloys using geometry tools with embedded helix after 1st and 5th passes through the ECAP tool. Figure 6 show selected readings stress-strain curves after selected passes through the channel for magnesium alloy AZ91 [14].

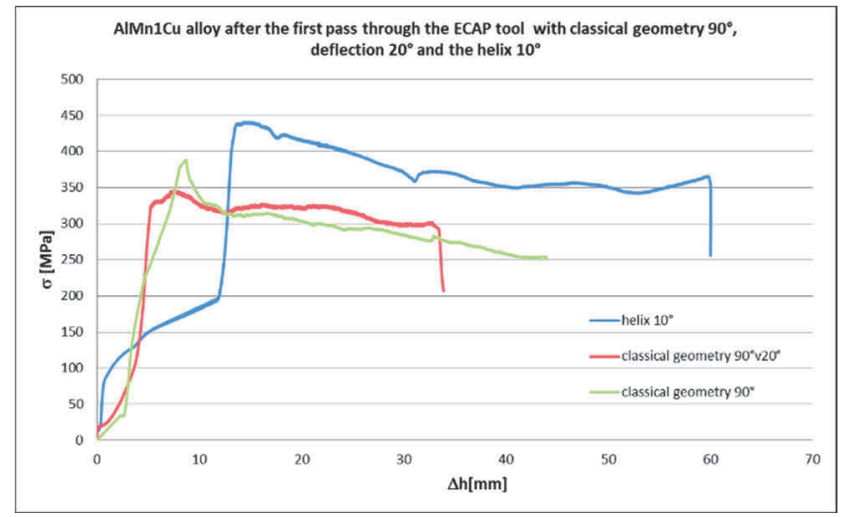

a)

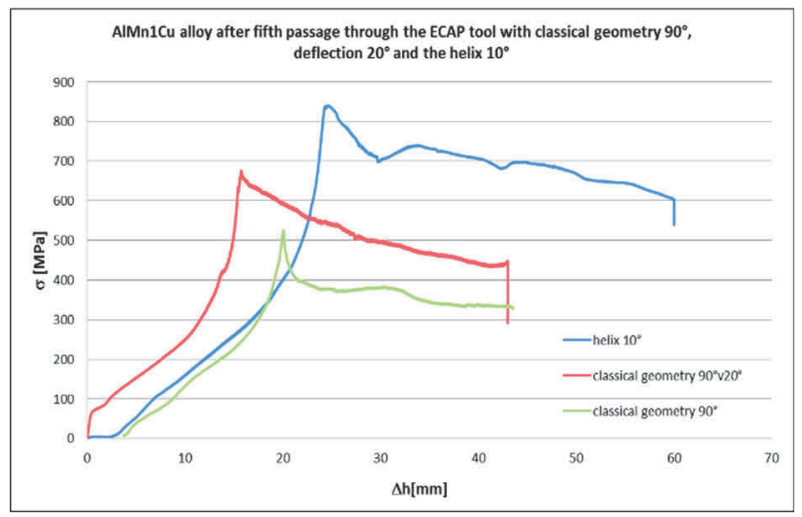

b)

Figure 5 The stress - strain curves of AIMn1Cu alloy

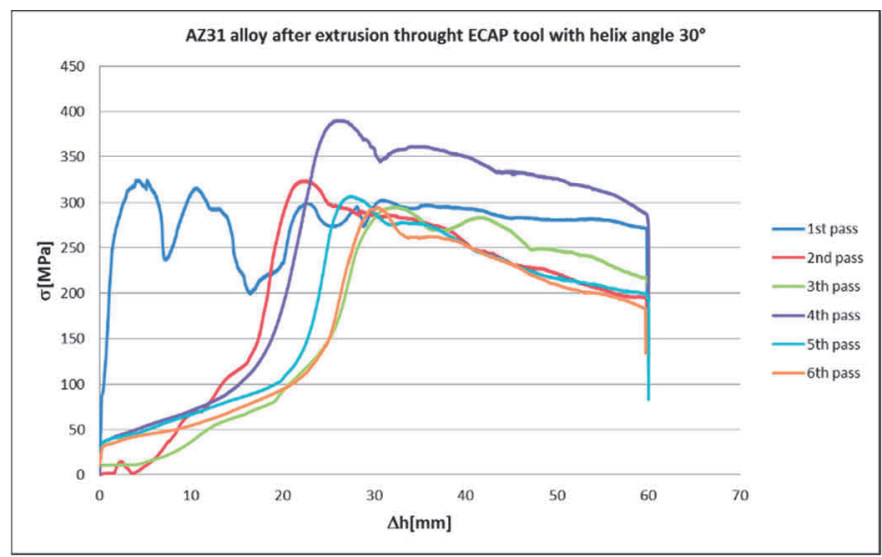

Figure 6 The stress - strain curves of magnesium alloy AZ31

\section{CONCLUSION}

The main aim of the experiments is a refinement of the structure of alloys AIMn1Cu using the minimum number of ECAP passes with special tools. To increase the degree of distortion, thereby achieving the desired structure is an important factor in appropriate modification tool geometry. Geometric adjustment of instruments is particularly evident in the new instrument ECAP helix is located $10^{\circ}$ in the horizontal part of the channel, which shows an overall increase in efficiency of the process of plastic deformation leading to greater refinement of the structure and obtain significantly better performance alloy AIMn1Cu.

\section{ACKNOWLEDGEMENTS}

The work was created under the national project of Grant Agency of Czech Republic GA No. 101/08/1110 and the Ministry of Education, Youth and sports of Czech Republic and project Nanoteam VSB-TU Ostrava, CZ.1.07/2.3.00/20.0038 and with cooperation of the Silesian University of Technology, Katowice which participated in project 2016/T02/2006/31 (financed by the MNSW, Poland). 


\section{REFERENCES}

[1] GUTKIN, M., OVIDKO, YU. et al. Theoretical models of plastic deformation processes in nano-crystalline materials. Rev. Adv. Mater. Sci. 2001, no. 2, pp. 80 - 102.

[2] SONG, R., PONGE, D. and RAABE, D. Grain boundary characterization and grain size measurement in an ultrafine grained steel. Max-Plank Institut for Eisenforschung. Düsseldorf, Germany. Z. Metallkd. 2004, vol. 95, no. 6, pp. 513-517.

[3] BERTA, M., ORLOV, D. and PRANGNELL, P. Grain refinement response during twist extrusion of an Al-0.13\% Mg alloy. International Journal of Materials Research. 2007, vol.98, issue 3. pp. 200-204.

[4] PETCH, N. J. The cleavage strength of polycrystals. Journal of the Iron and Steel Institute. 1953, vol. 174, pp. 2528.

[5] COTTRELL, A. H. Theory of brittle facture in steel and similar metals. Trans. Metallurgical Soc. AIME. 1958, vol. 212, pp. 192-203.

[6] MEYERS, M. A., BENSON, D. J. and Fu, H. H. Advanced Materials for the 21st Century. The Minerals, Metals and Materials Society, Warrendale, 1999.

[7] VALIEV, R. Z. Recent developments of severe plastic deformation techniques for processing bulk nanostructured materials. Materials Science Forum. 2008 vol. 579, pp. 1-14.

[8] ZHILYAEV, A. P., LANGDON, T., G. Using high-pressure torsion for metal processing: Fundamentals and applications. Progress in Materials Science. 2008, vol. 53, pp. 893-979.

[9] VARYUKHIN, V., BEYGELZIMER, Y. and EFROS, B. Nanostructured materials by twist extrusion and highpressure torsion. Materials Science Forum. 2008, vol. 584-586, pp.102-107.

[10] NAGASEKHAR, A.V., YOON, S.C., TICK-HON, Y. and KIM, H.S. An experimental verification of the finite element modeling of equal channel angular pressing. Computational Materials Science. 2009, vol. 46, pp. 347-351.

[11] YANG, Y.Q., LI, B.C. and ZHANG, Z.M. Flow stress of wrought magnesium alloys during hot compression deformation at medium and high temperatures. Materials Science and Engineering A. 2009, vol. 499, issues 1-2, pp. 238-241.

[12] KULYASOVA, O., ISLAMGALIEV, R., MINGLER, B. and ZEHETBAUER, M. Microstructure and fatigue properties of the ultrafine-grained AM60 magnesium alloy processed by equal-channel angular pressing. Materials Science and Engineering A. 2009, vol. 503, pp. 176-180.

[13] ESTRIN, Y., VINOGRADOV, A. Fatigue behaviour of light alloys with ultrafine grain structure produced by severe plastic deformation. International Journal of Fatigue. 2010, vol. 32, pp. 898-907.

[14] SONG, G.A., KIM, T.E., KIM, D.H., PRIMA, F. and KIM, K.B. Influence of hetero-duplex structure on mechanical properties of Mg-Al/Cu-Zn alloys. Materials Science and Engineering A. 2010, vol.528, pp. 371-378. 